ARTICLE

\title{
A rechargeable aqueous manganese-ion battery based on intercalation chemistry
}

\author{
Songshan $\mathrm{Bi}^{1}$, Shuai Wang ${ }^{1}$, Fang Yue ${ }^{1}$, Zhiwei $\operatorname{Tie}^{1} \&$ Zhiqiang Niu (i) ${ }^{1 凶}$
}

\begin{abstract}
Aqueous rechargeable metal batteries are intrinsically safe due to the utilization of low-cost and non-flammable water-based electrolyte solutions. However, the discharge voltages of these electrochemical energy storage systems are often limited, thus, resulting in unsatisfactory energy density. Therefore, it is of paramount importance to investigate alternative aqueous metal battery systems to improve the discharge voltage. Herein, we report reversible manganese-ion intercalation chemistry in an aqueous electrolyte solution, where inorganic and organic compounds act as positive electrode active materials for $\mathrm{Mn}^{2+}$ storage when coupled with a $\mathrm{Mn}$ /carbon composite negative electrode. In one case, the layered $\mathrm{Mn}_{0.18} \mathrm{~V}_{2} \mathrm{O}_{5} \cdot \mathrm{nH}_{2} \mathrm{O}$ inorganic cathode demonstrates fast and reversible $\mathrm{Mn}^{2+}$ insertion/ extraction due to the large lattice spacing, thus, enabling adequate power performances and stable cycling behavior. In the other case, the tetrachloro-1,4-benzoquinone organic cathode molecules undergo enolization during charge/discharge processes, thus, contributing to achieving a stable cell discharge plateau at about $1.37 \mathrm{~V}$. Interestingly, the low redox potential of the $\mathrm{Mn} / \mathrm{Mn}^{2+}$ redox couple vs. standard hydrogen electrode (i.e., $-1.19 \mathrm{~V}$ ) enables the production of aqueous manganese metal cells with operational voltages higher than their zinc metal counterparts.
\end{abstract}

\footnotetext{
${ }^{1}$ Key Laboratory of Advanced Energy Materials Chemistry (Ministry of Education), College of Chemistry, Nankai University, Tianjin 300071, P. R. China.

凶email: zqniu@nankai.edu.cn
} 
A queous rechargeable batteries are intrinsically safe due to the utilization of low-cost and nonflammable water-based electrolytes, thereby displaying robustness and cost advantages over competing for commercial lithium-ion batteries with volatile organic electrolytes ${ }^{1-5}$. Among various aqueous rechargeable batteries, those that pair metal anodes with various cathode materials are usually competitive in energy density because metal anodes provide much higher capacity and lower reduction potential than intercalation anodes. Up to now, $\mathrm{Zn}, \mathrm{Fe}$, and $\mathrm{Al}$ have been directly utilized as the anodes of aqueous rechargeable batteries since they are stable in aqueous electrolytes and possess high theoretical specific capacity ${ }^{6-10}$. Whereas the reduction potentials vs. standard hydrogen electrode (SHE) of $\mathrm{Zn}$ and Fe ( $\mathrm{Zn}:-0.76 \mathrm{~V}$, and Fe: $-0.44 \mathrm{~V}$ ) are high (Fig. 1a), resulting in low operating voltages of their corresponding aqueous batteries ${ }^{11,12}$. Compared with $\mathrm{Zn}$ and $\mathrm{Fe}, \mathrm{Al}$ possesses lower theoretical reduction potential $(-1.66 \mathrm{~V}$ vs. SHE). However, in fact, the practical reduction potential at $\mathrm{Al}$ anode is only around $-0.7 \mathrm{~V}$ vs. SHE in aqueous Al-ion batteries (AIBs), which would be ascribed to the large polarization of $\mathrm{Al}$ anodes ${ }^{13-16}$. As a result, the discharge voltages of aqueous AIBs are also limited ${ }^{17,18}$. In addition, the high charge density of $\mathrm{Al}^{3+}$ and the oxide layer on $\mathrm{Al}$ anode often result in unsatisfactory rate capability and poor cycling stability of aqueous AIBs ${ }^{19}$. Therefore, it is of great significance to explore other aqueous metal battery systems with both excellent electrochemical performance and promising futures in practical applications.
Manganese is the second most abundant transition metal near the Earth's surface. Owing to its high electronegativity, Mn metal also exhibits less reactivity and therefore reliable safety to be handled in water ${ }^{20,21}$. Furthermore, in theory, Mn possesses a low reduction potential $(-1.19 \mathrm{~V}$ vs. SHE) and high capacity $\left(7250 \mathrm{mAh} \mathrm{cm}^{-3}\right.$ and $976 \mathrm{mAh} \mathrm{g}^{-1}$, based on two-electron transfer reactions ${ }^{22}$. These properties of $\mathrm{Mn}$ make it a natural choice to act as the anode material in high-voltage aqueous batteries, where $\mathrm{Mn}$ ions will be employed as charge carriers. According to the standard electrode potentials, $\mathrm{Mn}$ ions could remain +2 valence in a wide voltage window $(\sim 2.4 \mathrm{~V})$ (Fig. $1 \mathrm{~b}$ ), which will ensure the stable $\mathrm{Mn}^{2+}$ ion transportation in electrolytes with a wide working voltage range. Therefore, rechargeable aqueous Mn-ion batteries (MIBs) could be feasible in principle and provide cost-effectiveness and considerably high energy density. However, to our best knowledge, there is hardly any report about $\mathrm{Mn}^{2+}$ ion charge carrier in battery research. Divalent $\mathrm{Mn}^{2+}$ ion holds a larger solvated ionic radius in aqueous electrolytes than the cases of most divalent ions, such as $\mathrm{Ca}^{2+}$, $\mathrm{Mg}^{2+}, \mathrm{Zn}^{2+}$, and $\mathrm{Fe}^{2+}$, indicating more difficulty of intercalating $\mathrm{Mn}^{2+}$ ions in common host materials. As a result, the implementation of aqueous MIBs hinges on the design of $\mathrm{Mn}^{2+}$ ion host materials with large interspacing channels and weak bond strengths between intercalated $\mathrm{Mn}^{2+}$ ions and host frameworks.

In this work, we reported the reversible $\mathrm{Mn}^{2+}$ intercalation chemistry in inorganic and organic compounds in aqueous battery systems (Fig. 1c). The $\mathrm{Mn}_{0.18} \mathrm{~V}_{2} \mathrm{O}_{5} \cdot n \mathrm{H}_{2} \mathrm{O}(\mathrm{MnVO})$ cathode is
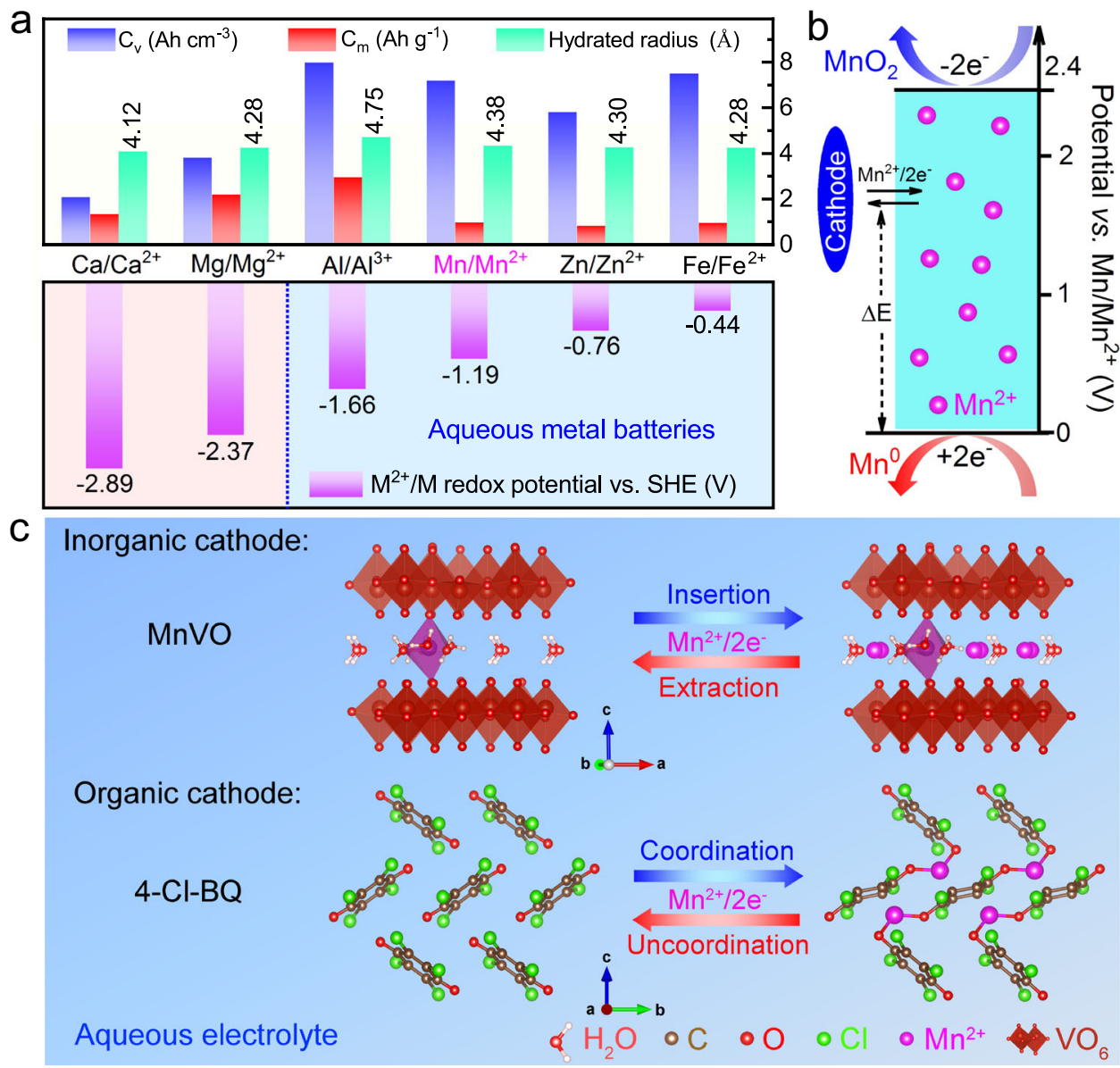

Fig. 1 Properties of $\mathbf{M n}^{\mathbf{2}+}$ ions in aqueous electrolytes. a Comparison of the theoretical capacity, hydrated ionic radius, and $M / M^{2+}$ redox potential vs. $\mathrm{SHE}$ of various multivalent metals, including $\mathrm{Ca}, \mathrm{Mg}, \mathrm{Al}, \mathrm{Mn}, \mathrm{Zn}$, and Fe. $\mathbf{b}$ The stable voltage window of $\mathrm{Mn}^{2+}$ ions. c Schematic diagram of different $\mathrm{Mn}^{2+}$ ion reaction processes in inorganic $(\mathrm{MnVO})$ and organic $(4-\mathrm{Cl}-\mathrm{BQ})$ cathodes. 
first selected as the host material of $\mathrm{Mn}^{2+}$ ions. Its large lattice spacing enables a fast and reversible $\mathrm{Mn}^{2+}$ ion insertion/extraction process, leading to high power density and stable cycling performance. In addition to MnVO, the quinone molecule, tetrachloro-1,4-benzoquinone (4-Cl-BQ), undergoes the enolization redox chemistry in the charge/discharge process with a stable discharge plateau. More impressively, the low redox potential vs. SHE of $\mathrm{Mn} / \mathrm{Mn}^{2+}$ endows the resultant aqueous $\mathrm{Mn}$ metal batteries with high operating voltages. These results indicate the feasibility of $\mathrm{Mn}^{2+}$ ion intercalation in different cathodes as well as the promising future of aqueous MIBs.

\section{Results}

Design toward aqueous MIBs. Towards rechargeable aqueous MIBs, $\mathrm{Mn}^{2+}$ ion dissociation from aqueous electrolytes and solidstate ion diffusion in cathodes are two essential steps during the charge/discharge process $^{23}$. Therefore, it is of great importance to explore suitable electrolytes and cathode materials of MIBs. In common aqueous metal-ion battery systems, electrolytes are usually obtained via dissolving metal salts into water, where metal cations act as charge carriers. In addition to metal cations, anions in electrolytes also play an important role in the electrochemical performance of aqueous metal-ion batteries since their redox activity would affect the electrochemical window of electrolytes and the compatibility with electrodes ${ }^{24}$. Moreover, the coordination capability of anions with metal cations also determines the metal ion intercalation process. $\mathrm{MnCl}_{2}, \mathrm{Mn}\left(\mathrm{NO}_{3}\right)_{2}, \mathrm{MnSO}_{4}$, and $\mathrm{Mn}\left(\mathrm{CF}_{3} \mathrm{SO}_{3}\right)_{2}$ are the common manganese salts, which could be employed as the aqueous electrolytes via dissolving them into water. To understand the electrochemical window of MIBs with these aqueous electrolytes, the cells were assembled, where Mn/C composite and stainless steel served as anode and cathode, respectively. It is noted that the electrolyte decomposition will occur after 1.7 and $1.5 \mathrm{~V}$ in $1 \mathrm{M} \mathrm{MnCl}_{2}$ and $\mathrm{Mn}\left(\mathrm{NO}_{3}\right)_{2}$ aqueous electrolytes, respectively (Supplementary Fig. 1), which was due to that $\mathrm{Cl}^{-}$and $\mathrm{NO}_{3}{ }^{-}$possess high redox activity ${ }^{24,25}$. Therefore, $\mathrm{MnCl}_{2}$ and $\mathrm{Mn}\left(\mathrm{NO}_{3}\right)_{2}$ aqueous electrolytes are not feasible for aqueous MIBs. In contrast, $\mathrm{SO}_{4}{ }^{2-}$ and $\mathrm{CF}_{3} \mathrm{SO}_{3}{ }^{-}$possess stable structures $^{24}$, indicating the high electrochemical stability and compatibility with electrodes. The electrochemical window could reach $\sim 2.0 \mathrm{~V}$ within $\mathrm{MnO}_{2}$ deposition and $\mathrm{H}_{2}$ evolution potentials in these two electrolytes (Supplementary Fig. 2). Moreover, Mn metal could be electrodeposited on stainless steel at a low potential (Supplementary Fig. 3), indicating the feasibility of $\mathrm{MnSO}_{4}$ and $\mathrm{Mn}\left(\mathrm{CF}_{3} \mathrm{SO}_{3}\right)_{2}$ solutions to act as the electrolytes of aqueous MIBs. The contact angles of $\mathrm{MnSO}_{4}$ and $\mathrm{Mn}\left(\mathrm{CF}_{3} \mathrm{SO}_{3}\right)_{2}$ electrolytes were measured. Electrolyte droplets $(\sim 5 \mu \mathrm{L})$ were dropped on the surface of the $\mathrm{MnVO}$ cathode and then let it stand for $5 \mathrm{~s}$. Compared with $\mathrm{MnSO}_{4}$ electrolyte, $\mathrm{Mn}\left(\mathrm{CF}_{3} \mathrm{SO}_{3}\right)_{2}$ electrolyte exhibits greater hydrophilicity on cathode due to the existence of $\mathrm{CF}_{3}$ groups (Supplementary Figs. 4 and 5), which will be beneficial to the infiltration of electrolyte into active materials. Besides, the bulky $\mathrm{CF}_{3} \mathrm{SO}_{3}{ }^{-}$anions could also reduce the solvation effect of metal ions, facilitating metal ion transportation and charge transfer ${ }^{25,26}$. As a result, $\mathrm{Mn}\left(\mathrm{CF}_{3} \mathrm{SO}_{3}\right)_{2}$ electrolytes would be the better choice to act as the electrolyte of aqueous MIBs.

Apart from electrolytes, cathode materials also determine the ion insertion thermodynamics and kinetics in aqueous batteries. Different from other divalent metal ions, $\mathrm{Mn}^{2+}$ ions possess a large solvated ionic radius and enhanced interaction with frameworks of host materials, which will limit the insertion/ extraction of $\mathrm{Mn}^{2+}$ ions in common host materials. Among cathode candidates, metal oxides are perspective due to their low cost and high valence of metal centers ${ }^{27}$. In consideration of the multivalence of vanadium and large lattice spacing, layered vanadium-based compounds exhibit promising to function as $\mathrm{Mn}^{2+}$ ion host materials. Furthermore, the interlayer spacing of layered vanadium-based compounds can be adjusted by introducing metal ions and structural water molecules ${ }^{28-30}$. The introduced metal ions in the interlayers can act as pillars to enhance their structural stability during the charge/discharge process. The structural water molecules between $\mathrm{V}_{x} \mathrm{O}_{y}$ layers could reduce the effective charge of metal ions by solvation, accelerating metal ion diffusion ${ }^{31}$. Therefore, in our case, we designed an $\mathrm{Mn}^{2+}$ ion pre-intercalated hydrated vanadium oxide (MnVO) as the cathode material of aqueous MIBs to accommodate the $\mathrm{Mn}^{2+}$ ion charge carriers (Supplementary Figs. 6-9 and Supplementary Note 1).

In addition to layered inorganic materials, organic compounds can also serve as the cathode materials of aqueous metal-ion batteries by the coordination/uncoordination chemistry, which is different from the insertion/extraction mechanism in inorganic compounds and usually not governed by the radius and charge of charge carriers ${ }^{32}$. Furthermore, organic materials are sustainable and their structures can be designed flexibly, which offers the potential for the concomitant binding with $\mathrm{Mn}^{2+}$ ions $^{33}$. Therefore, aqueous Mn\|organic cells could be realized by designing appropriate organic compounds, which will broaden the horizons of MIBs. Quinones exhibit a highly reversible transition process between $\mathrm{C}=\mathrm{O}$ and $\mathrm{C}_{-} \mathrm{O}^{-}$groups during electrochemical redox reactions ${ }^{34,35}$. Furthermore, the introduction of electron-withdrawing groups (such as $-\mathrm{CN},-\mathrm{F},-\mathrm{Cl}$, and $-\mathrm{Br}$ ) into quinones could improve their operating voltages ${ }^{33}$. Thus, in our case, 4-Cl-BQ was selected as the cathode material to assemble an aqueous $\mathrm{Mn} \|$ organic cell.

$\mathrm{Mn}^{2+}$ insertion in MnVO cathodes. To understand the $\mathrm{Mn}^{2+}$ ion insertion in $\mathrm{MnVO}, \mathrm{Mn}|| \mathrm{MnVO}$ coin cells were assembled with $\mathrm{Mn} / \mathrm{C}$ anodes, $\mathrm{MnVO}$ cathodes, and aqueous $\mathrm{Mn}\left(\mathrm{CF}_{3} \mathrm{SO}_{3}\right)_{2}$ electrolytes (Supplementary Fig. 10). The Mn\|MnVO cell displays a pair of reversible reduction/oxidation peaks located at $1.27 / 1.39 \mathrm{~V}$ in their cyclic voltammetry (CV) curves (Fig. 2a), which could be ascribed to a one-step $\mathrm{Mn}^{2+}$ ion insertion/ extraction process. Moreover, their CV curves exhibit similar shapes at the initial three cycles (Supplementary Fig. 11a), revealing the highly reversible redox behaviors. Their galvanostatic charge/discharge (GCD) curves are consistent well with the $\mathrm{CV}$ results. The $\mathrm{Mn} \| \mathrm{MnVO}$ cell delivers an average discharge voltage of around $1.33 \mathrm{~V}$ and a capacity of $133.7 \mathrm{mAh} \mathrm{g}^{-1}$ at $0.2 \mathrm{~A} \mathrm{~g}^{-1}$ (Supplementary Fig. 11b), corresponding to a $\sim 1.1$ electron redox process. In addition, there is nearly no deviation in the GCD curves at the initial 20 cycles (Fig. 2b), indicating that the $\mathrm{Mn} \| \mathrm{MnVO}$ cell shows stable $\mathrm{Mn}^{2+}$ ion insertion/extraction performance. Moreover, capacity retention of $86.7 \%$ was achieved at a specific current of $5.0 \mathrm{Ag}^{-1}$ after 200 cycles (Fig. 2c). A similar reaction process was also observed in $\mathrm{Mn} \| \mathrm{MnVO}$ cells with aqueous $\mathrm{MnSO}_{4}$ electrolyte. However, the $\mathrm{Mn}|| \mathrm{MnVO}$ cell exhibits a larger polarization voltage in $\mathrm{MnSO}_{4}$ electrolyte than that in $\mathrm{Mn}\left(\mathrm{CF}_{3} \mathrm{SO}_{3}\right)_{2}$ electrolyte. Besides, in the case of $\mathrm{MnSO}_{4}$ electrolyte, the capacity undergoes a rapid decay at cycling process (see Fig. 2b). The performance of the $\mathrm{Mn} \| \mathrm{MnVO}$ cells with $\mathrm{Mn}\left(\mathrm{CF}_{3} \mathrm{SO}_{3}\right)_{2}$ electrolyte is ascribed to that the $\mathrm{CF}_{3} \mathrm{SO}_{3}^{-}$anions could decrease the solvation effect of $\mathrm{Mn}^{2+}$ ions in aqueous solution, facilitating $\mathrm{Mn}^{2+}$ ions insertion/extraction process (Supplementary Fig. 12 and Supplementary Table 1). Therefore, $\mathrm{Mn}\left(\mathrm{CF}_{3} \mathrm{SO}_{3}\right)_{2}$ electrolyte was further selected for the $\mathrm{Mn}^{2+}$ ion reaction kinetics and mechanism analysis in $\mathrm{MnVO}$ electrodes.

The insertion/extraction kinetics of $\mathrm{Mn}^{2+}$ ions in the $\mathrm{MnVO}$ electrode could be understood by their CV curves at different scan rates. The reduction/oxidation peaks in $\mathrm{CV}$ curves are still 

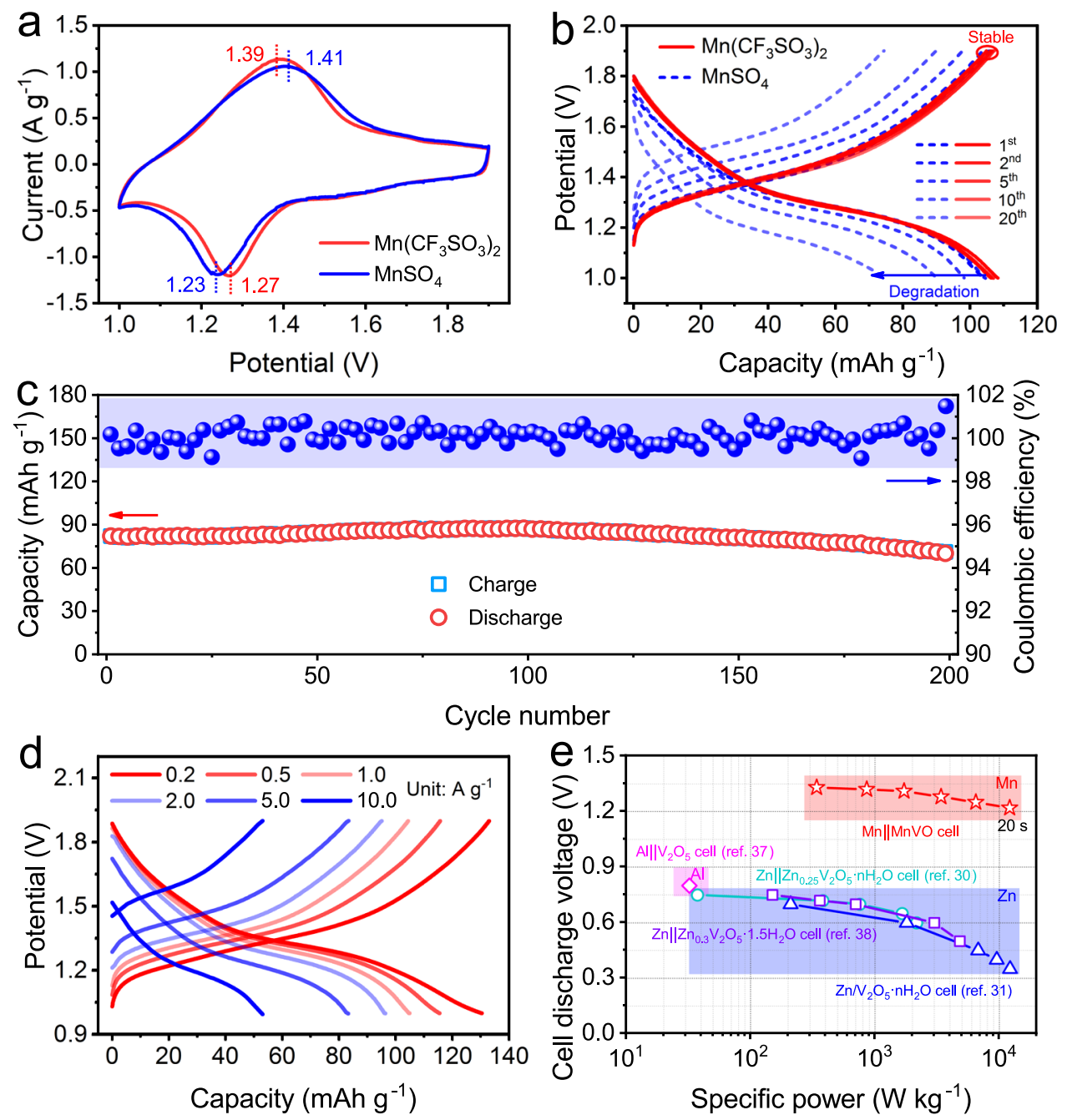

Fig. 2 Electrochemical performance of the $\mathbf{M n | | M n V O}$ cells. a CV curves at $1.0 \mathrm{mV} \mathrm{s}^{-1}$ and $\mathbf{b} \mathrm{GCD}$ curves at $1.0 \mathrm{Ag}^{-1}$ in $1 \mathrm{M} \mathrm{MnSO}_{4}$ and $\mathrm{Mn}\left(\mathrm{CF}_{3} \mathrm{SO}_{3}\right)_{2}$ electrolytes. c Cycling performance at $5.0 \mathrm{~A} \mathrm{~g}^{-1}$ in $1 \mathrm{M} \mathrm{Mn}\left(\mathrm{CF}_{3} \mathrm{SO}_{3}\right)_{2}$ electrolyte. d GCD curves at different specific currents. e Comparison of the cell discharge voltage and specific power between various vanadium-based aqueous metal cells.

detectable at high scan rates (Supplementary Fig. 13a). The relationship between peak currents $(i)$ and scan rates $(v)$ could be written as follows ${ }^{36}$.

$$
i=a v^{b}
$$

which could be rearranged to

$$
\log (i)=b \log (v)+\log (a)
$$

where $b$ is the slope of $\log (i)$ vs. $\log (v)$ curve. The $b$ value approaching to 0.5 indicates an ionic diffusion-controlled electrochemical process. When $b$ value reaches 1 , the charge/discharge process is determined by pseudocapacitance. By fitting the plots of $\log (i)$ vs. $\log (v)$, the $b$ values for oxidation and reduction peaks are fitted as 0.68 and 0.71 (Supplementary Fig. 13b), suggesting that the charge/discharge process in $\mathrm{Mn}|| \mathrm{MnVO}$ cells is controlled by ionic diffusion and pseudocapacitance synergistically. This characteristic contributes to the rate capability performance of the $\mathrm{Mn} \|$ MnVO cells, where a considerable capacity of $83.3 \mathrm{mAh} \mathrm{g}^{-1}$ could still be obtained even at a specific current of $5.0 \mathrm{~A} \mathrm{~g}^{-1}$ (Fig. $2 \mathrm{~d}$ and Supplementary Fig. 14). The typical discharge plateau is maintained at $1.25 \mathrm{~V}$, which is higher than the cases of the state-of-theart vanadium-based aqueous metal batteries, including $\mathrm{Al}|| \mathrm{V}_{2} \mathrm{O}_{5}$ cells $(0.8 \mathrm{~V})$ and $\mathrm{Zn} \| \mathrm{Zn}_{x} \mathrm{~V}_{2} \mathrm{O}_{5} \cdot n \mathrm{H}_{2} \mathrm{O}$ cells $(<0.75 \mathrm{~V})^{30,31,37,38}$. Furthermore, the Mn\|MnVO cells could also deliver a specific power of $12.1 \mathrm{~kW} \mathrm{~kg}^{-1}$ at $10.0 \mathrm{~A} \mathrm{~g}^{-1}$ (Fig. 2e), which is comparable with the high-rate aqueous $\mathrm{Zn} \| \mathrm{V}_{2} \mathrm{O}_{5} \cdot n \mathrm{H}_{2} \mathrm{O}$ cells $\left(12.2 \mathrm{~kW} \mathrm{~kg}^{-1}\right)$ and much higher than that of the aqueous $\mathrm{Al} \|$ $\mathrm{V}_{2} \mathrm{O}_{5}$ cells $\left(<50 \mathrm{~W} \mathrm{~kg}^{-1}\right)^{31,37}$. At such specific power, the charging process was fully completed in $20 \mathrm{~s}$ with a specific energy of 64.8 $\mathrm{Wh} \mathrm{kg}^{-1}$.

Ex situ measurements and analyses of the MnVO-based inorganic electrode. The energy storage process plays an important role in the electrochemical performance of $\mathrm{Mn} \| \mathrm{MnVO}$ cells. Thus, various measurements, including X-ray diffraction (XRD), transmission electron microscopy (TEM), X-ray photoelectron spectroscopy (XPS), Raman and Fourier transform infrared (FTIR), were conducted on MnVO electrodes at selected states in the charge/discharge process to understand the energy storage mechanism (Fig. 3a). In XRD spectra, compared to a pristine state, no new reflection is observed and only the reflection of the (001) plane shifts slightly toward a high degree during the discharge process (Fig. 3b, c), suggesting the decrease of the corresponding interlayer spacing due to the $\mathrm{Mn}^{2+}$ ion insertion in the interlayer of MnVO (Supplementary Fig. 15). The $\mathrm{Mn}^{2+}$ ion insertion/extraction mechanism in MnVO cathodes is further demonstrated by energy-dispersive X-ray (EDX) spectrum results of TEM, in which the molar ratio of $\mathrm{Mn} / \mathrm{V}$ elements increases in 


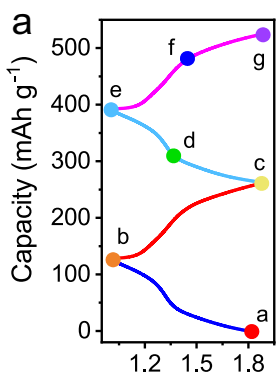

Potential (V)
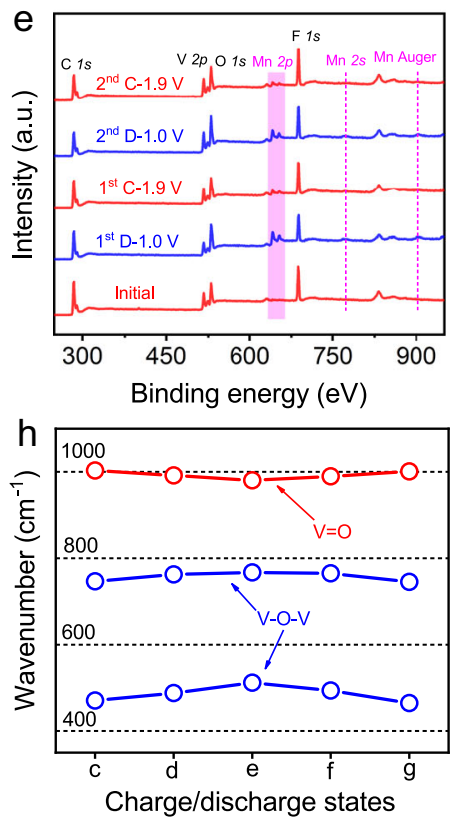
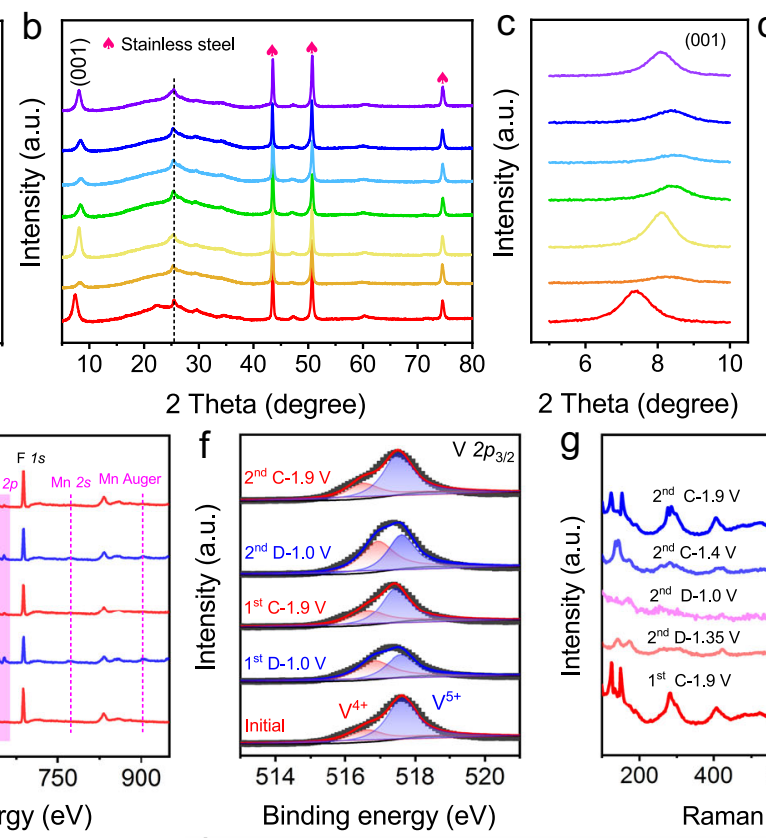

2 Theta (degree)
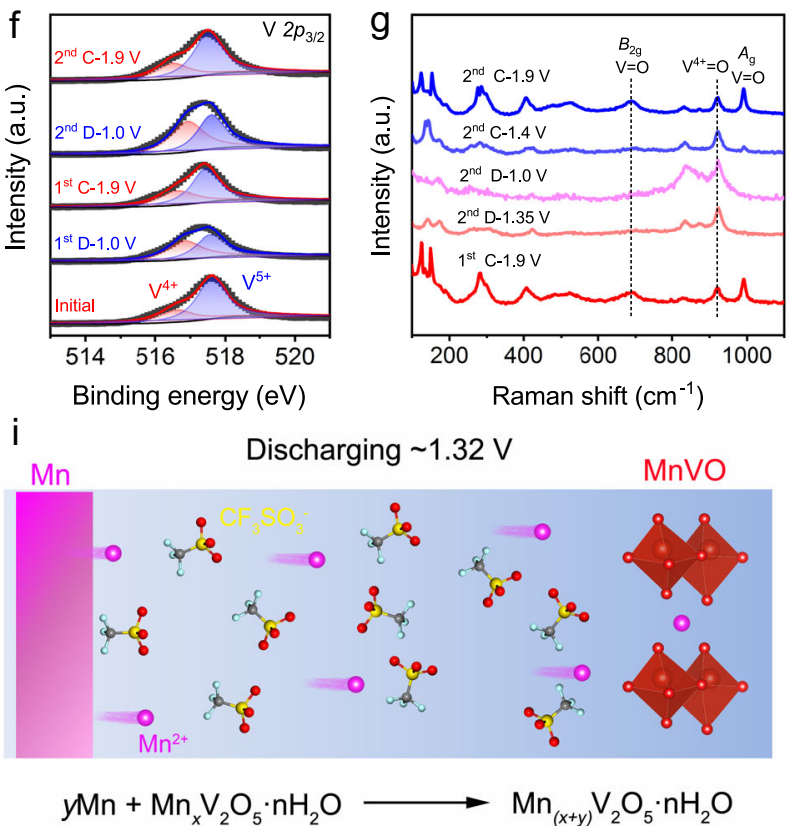

Fig. $3 \mathbf{M n}^{2+}$ insertion mechanism in MnVo electrodes. a The initial two GCD curves at $0.2 \mathrm{Ag}^{-1}$. $\mathbf{b}$ XRD patterns at different charge/discharge states. c An enlarged view of the (001) reflection from the XRD patterns in (b). d TEM element mapping in fully discharged electrodes. Scale bar: $200 \mathrm{~nm}$. XPS spectra of $\mathbf{e}$ full-spectrum and $\mathbf{f} \vee 2 p_{3 / 2}$ at fully discharged/charged states. $\mathbf{g}$ Raman and $\mathbf{h}$ FTIR spectra at the selected charge/discharge states. $\mathbf{i}$ Schematic diagram of the discharging mechanism of $\mathrm{Mn} \| \mathrm{MnVO}$ cells.

fully discharged electrodes and then decreases in recharged case (Fig. 3d and Supplementary Figs. 16 and 17). Moreover, in XPS spectra, the peaks of Mn 2p, Mn 2s, and Mn Auger are significantly strengthened in $\mathrm{MnVO}$ electrodes at a fully discharged state (Fig. 3e). Reversibly, during the subsequent charging process, the intensities of these peaks are weakened. Therefore, XPS results also suggest the reversible $\mathrm{Mn}^{2+}$ insertion/extraction in $\mathrm{MnVO}$ cathodes. Inductively coupled plasma atomic emission spectroscopy (ICP-AES) shows that the molar ratios of $\mathrm{Mn}$ and $\mathrm{V}$ in the discharged and charged products are 0.385:1 (first discharge at $1.0 \mathrm{~V}$ ) and 0.097:1 (first charge at $1.9 \mathrm{~V}$ ), respectively (Supplementary Fig. 18 and Supplementary Table 2). Therefore, in the charging process, the amount of the extracted $\mathrm{Mn}^{2+}$ is 0.576 in per formula unit of $\mathrm{MnVO}$, corresponding to a $\sim 1.15$ electron redox process (at $\left.0.2 \mathrm{Ag}^{-1}\right)$. It agrees well with the charge/discharge capacities.

The insertion/extraction of $\mathrm{Mn}^{2+}$ ion will lead to the valence change of vanadium in MnVO cathodes, as illustrated in V $2 p$ XPS spectra at different charge/discharge states (Fig. 3f). At a fully discharged state, the peak of $\mathrm{V} 2 p_{3 / 2}$ shifts to lower bonding energy, corresponding to the reduction of vanadium. After recharging, it nearly recovers to the initial state since vanadium is oxidized along with the $\mathrm{Mn}^{2+}$ extraction. The vanadium redox reaction can also be investigated via Raman and FTIR measurements and analyses. During $\mathrm{Mn}^{2+}$ insertion, the Raman peaks between 850 and $950 \mathrm{~cm}^{-1}$ appear and enhance gradually (Fig. 3g), which is attributed to the $\mathrm{V}^{5+} / \mathrm{V}^{4+}$ transition $^{39}$. In FTIR spectra, the peaks of $\mathrm{V}=\mathrm{O}$ and $\mathrm{V}-\mathrm{O}-\mathrm{V}$ bonds shift to lower and higher wavenumber, respectively (Fig. $3 \mathrm{~h}$ ), suggesting the weakening of $\mathrm{V}=\mathrm{O}$ bonds and strengthening of $\mathrm{V}-\mathrm{O}-\mathrm{V}$ bonds ${ }^{40,41}$. In the subsequent recharging process, these peaks almost return to the initial state, revealing the high reversibility of the $\mathrm{V}^{5+} / \mathrm{V}^{4+}$ transition. In addition, there is no peak emerging at around $3500 \mathrm{~cm}^{-1}$ (Supplementary Fig. 19), which is assigned to $-\mathrm{OH}$ bend ${ }^{37}$, indicating that the protons in the electrolyte would not insert into the MnVO cathode in our case. Thus, the insertion/extraction of $\mathrm{Mn}^{2+}$ ions is realized in $\mathrm{Mn} \|$ organic cell (Fig. 3i).

$\mathrm{Mn}^{2+}$ coordination in organic cathodes. Organic compounds are also promising $\mathrm{Mn}^{2+}$ ion host materials in consideration of their potentially sustainable production and structural variability ${ }^{32}$. To illustrate the feasibility of $\mathrm{Mn}^{2+}$ ion coordination in organic materials, 4-Cl-BQ was employed as the cathode material of aqueous Mn||organic cells due to its high capacity and flat cell discharge voltage in aqueous $\mathrm{Zn}$-ion cells ${ }^{42}$. In general, organic materials suffer from poor electronic conductivity, which would limit their rate capability. Furthermore, the discharged products of quinones always face serious dissolution in aqueous electrolytes, degrading cycling stability ${ }^{43,44}$. Therefore, 4-Cl-BQ molecules 

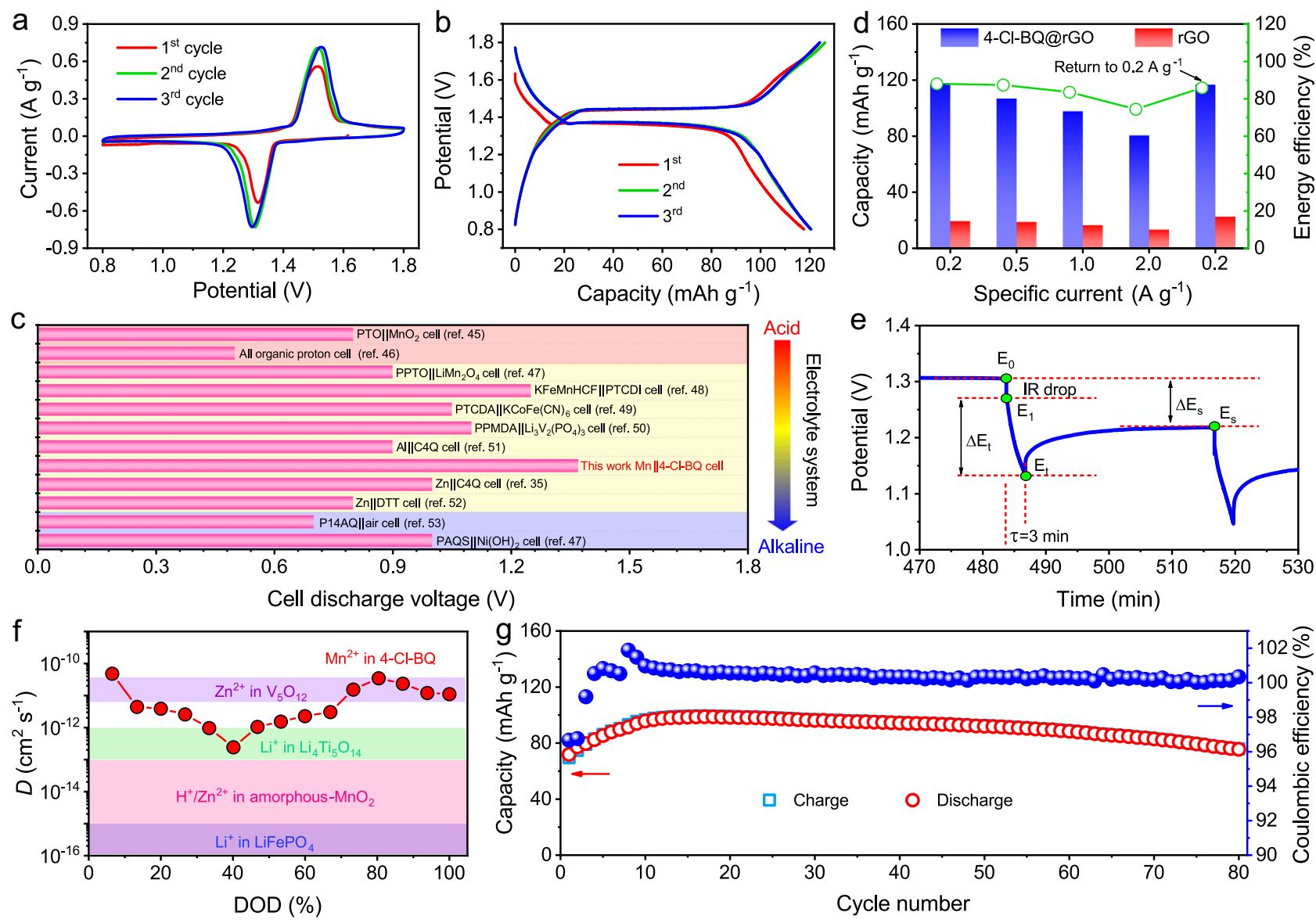

Fig. 4 Electrochemical performance of the $\mathbf{M n} \| \mathbf{4}-\mathbf{C l}-\mathbf{B Q}$ cells. a $\mathrm{CV}$ curves at $0.2 \mathrm{mV} \mathrm{s}^{-1}$. $\mathbf{b} \mathrm{GCD}$ curves at $0.2 \mathrm{Ag}^{-1}$. c Comparison of the cell discharge voltages between different aqueous quinone-based cells in acid, mild and alkaline electrolytes. $\mathbf{d}$ Capacities of rGO and 4-Cl-BQ@rGO composites at different specific currents. The right $y$-axis is the energy efficiency of $\mathrm{Mn} \| 4-\mathrm{Cl}-\mathrm{BQ}$ cells. e Selected steps of the GITT curve at $0.2 \mathrm{~A} \mathrm{~g}^{-1}$ during discharging, in which the key parameters for diffusion coefficient calculation are marked. $\mathbf{f}$ The calculated $\mathrm{Mn}^{2+}$ ion diffusion coefficient during discharging and the comparison with other battery systems. $\mathbf{g}$ Cycling performance at $1.0 \mathrm{~A} \mathrm{~g}^{-1}$.

were introduced into reduced graphene oxide (rGO) foams, which possess conductive and continuous networks (Supplementary Figs. 20-23 and Supplementary Note 2). Since the resultant 4-Cl-BQ@rGO composite foams are conductive and freestanding, they can serve as the cathodes directly, where neither polymer binders nor conductive additives are required. The $\mathrm{CV}$ curves of $\mathrm{Mn}|| 4-\mathrm{Cl}-\mathrm{BQ}$ cell show one pair of redox peaks located at $1.29 / 1.53 \mathrm{~V}$, indicating one-step coordination/uncoordination reaction during the discharge/charge process (Fig. 4a). Correspondingly, in GCD curves, the Mn||4-Cl-BQ cell delivers a stable discharge plateau at around $1.37 \mathrm{~V}\left(0.2 \mathrm{Ag}^{-1}\right)$ (Fig. 4b). The discharge voltage is higher than the cases of those reported aqueous batteries with quinone electrodes in various electrolytes (Fig. 4c $)^{35,45-53}$. The higher discharge voltage is attributed to the redox potential of $\mathrm{Mn} / \mathrm{Mn}^{2+}$ being lower than the cases of intercalation anodes and other metal anodes ( $\mathrm{Al}$ and $\mathrm{Zn})$ in aqueous batteries.

Apart from high and stable discharge voltage, the aqueous $\mathrm{Mn} \|$ 4-Cl-BQ cells also exhibit good cycling rate performances and energy efficiency (Fig. 4d). The cell could deliver a capacity of around $80.6 \mathrm{mAh} \mathrm{g}^{-1}$ at $2.0 \mathrm{~A} \mathrm{~g}^{-1}$, maintaining $68.5 \%$ of that at $0.2 \mathrm{~A} \mathrm{~g}^{-1}$ (Supplementary Fig. 24), which suggests the fast kinetics of $\mathrm{Mn}^{2+}$ ion coordination/uncoordination in 4-Cl-BQ molecules. The galvanostatic intermittent titration technique (GITT) was further employed to understand the diffusion coefficient of $\mathrm{Mn}^{2+}$ ions in 4-Cl-BQ@rGO composite cathodes. The Mn\|4-Cl-BQ cell was discharged at $0.2 \mathrm{Ag}^{-1}$ with an interval of $3 \mathrm{~min}$ and then relaxed for $30 \mathrm{~min}$ to allow the voltage to reach equilibrium (Supplementary Fig. 25). The $D_{\text {ion }}$ was calculated according to the equation ${ }^{54}$ :

$$
D_{\text {ion }}=\frac{4}{\pi t}\left(\frac{m V_{m}}{M S}\right)^{2}\left(\frac{\triangle E_{S}}{\triangle E_{\tau}}\right)^{2}
$$

in which $\tau$ is the duration time (s) of the current pulse and $m$ is the weight of 4 -Cl-BQ (g). $M$ and $V_{m}$ are the corresponding molar mass $\left(\mathrm{g} \mathrm{mol}^{-1}\right)$ and volume $\left(\mathrm{cm}^{3} \mathrm{~mol}^{-1}\right)$ of 4-Cl-BQ, respectively. $S$ is the contact area $\left(\mathrm{cm}^{2}\right)$ between electrode and electrolyte. $\Delta E_{s}$ and $\Delta E_{\tau}$ are related to the change of discharge voltage and steadystate voltage for the corresponding steps (Fig. 4e). GITT result shows that the diffusion coefficient of $\mathrm{Mn}^{2+}$ ions in 4-Cl-BQ@rGO composite cathode is $\sim 10^{-12}-10^{-10} \mathrm{~cm}^{2} \mathrm{~s}^{-1}$, which is higher than the $\mathrm{Li}^{+}$ion diffusion coefficients in $\mathrm{LiFePO}_{4}$ and $\mathrm{Li}_{4} \mathrm{Ti}_{5} \mathrm{O}_{12}$ $\left(<10^{-12} \mathrm{~cm}^{2} \mathrm{~s}^{-1}\right)$ (Fig. 4f $)^{49}$. Furthermore, it is comparable with the $\mathrm{Zn}^{2+}$ ion diffusion coefficient in $\mathrm{V}_{5} \mathrm{O}_{12}$ and higher than the $\mathrm{H}^{+} / \mathrm{Zn}^{2+}$ ion diffusion coefficient in amorphous $\mathrm{MnO}_{2}{ }^{54,55}$. In addition, the introduction of rGO foams in cathodes endows the Mn||4-Cl-BQ cells with relatively stable cycling performance (Fig. 4g). Initially, the 4-Cl-BQ@rGO composite cathodes deliver a capacity of $71.9 \mathrm{mAh} \mathrm{g}^{-1}$ at $1.0 \mathrm{Ag}^{-1}$. After 80 cycles, the capacity still remains at $75.6 \mathrm{mAh}^{-1}$.

Ex situ measurements and analyses of the 4-Cl-BQ-based organic electrode. Different from the insertion/extraction energy 

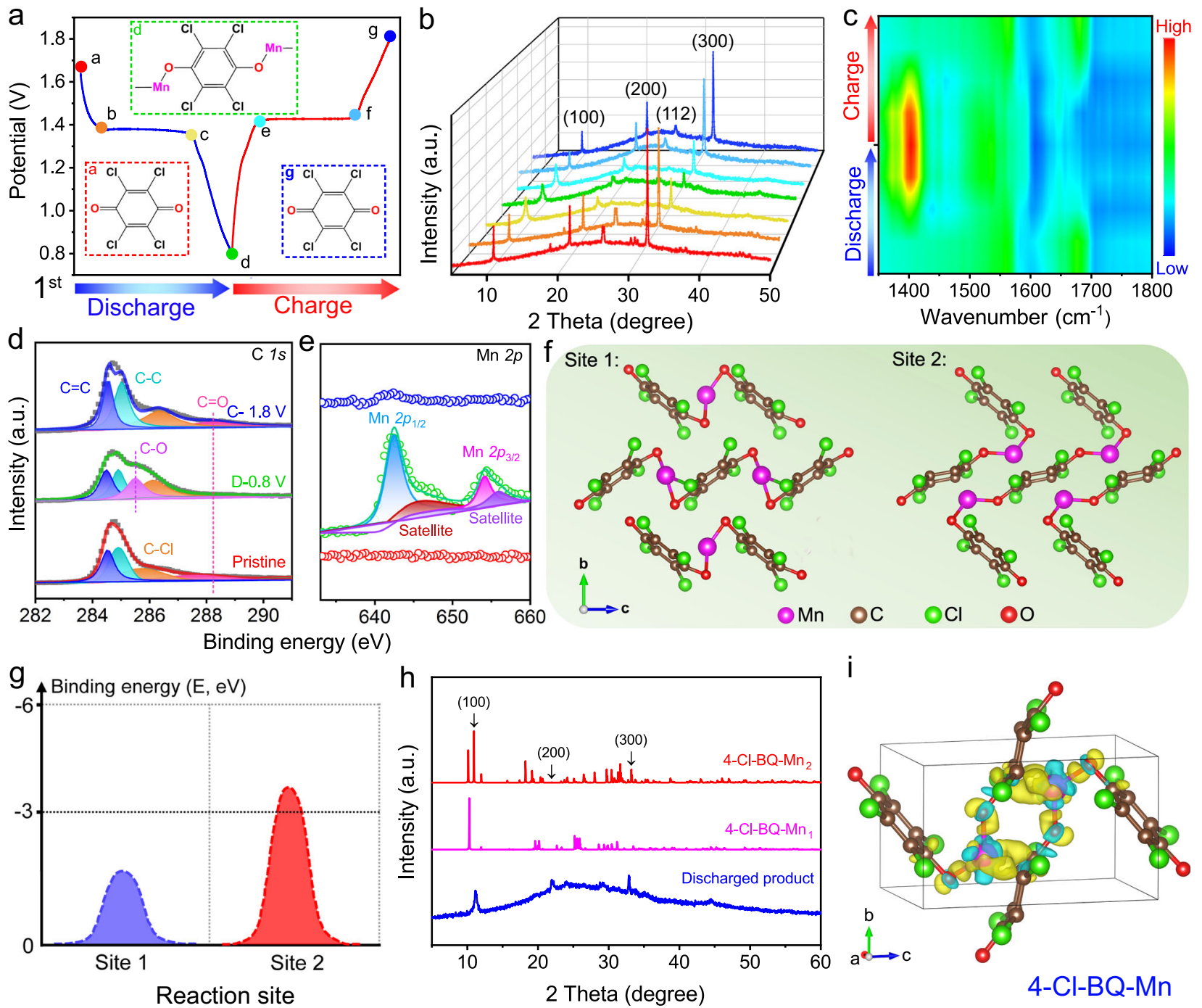

Fig. $5 \mathbf{~ M n}^{2+}$ ion coordination mechanism in 4-Cl-BQ electrodes. a The first GCD curve at $50 \mathrm{~mA} \mathrm{~g}^{-1}$. Inserts are the schematic diagrams of 4-Cl-BQ molecules at different discharge/charge states. b XRD patterns, c FTIR, XPS spectra of $\mathbf{d}$ C $1 s$ and $\mathbf{e}$ Mn $2 p$ at different discharge/charge states. f Schematic diagram and $\mathbf{g}$ calculated binding energy of two possible coordination sites of $\mathrm{Mn}^{2+}$ ions in 4-Cl-BQ crystals. $\mathbf{h}$ The predicted XRD patterns of two possible coordination sites and the XRD pattern of the discharged product. i Differential charge densities of $\mathrm{Mn}^{2+}$ ion coordinated 4-Cl-BQ crystals. Blue and yellow indicate electron accumulation and depletion, respectively.

storage mechanism in inorganic materials, 4-Cl-BQ molecules often exhibit the coordination/uncoordination chemistry in the discharge/charge process. In our case, the energy storage mechanism of the $4-\mathrm{Cl}-\mathrm{BQ}$ cathode was investigated via a series of ex situ tests, including XRD, XPS, and FTIR at the selected states in the first cycle (Fig. 5a). As shown in XRD patterns, the sharp reflections at $21.7^{\circ}, 26.6^{\circ}$, and $32.7^{\circ}$ belonging to (200), (112) and (300) planes, get weakened during discharging (Fig. 5b), which is due to that the ion coordination process degrades the crystallinity of 4-Cl-BQ. The 4-Cl-BQ undergoes the enolization redox chemistry in the charge/discharge process, as suggested by FTIR spectra. During the discharge process, the peak intensity of the $\mathrm{C}=\mathrm{O}$ group vibration (stretching vibration: $1655 \mathrm{~cm}^{-1}$ ) gradually declines, indicating the reaction between $\mathrm{Mn}^{2+}$ ions and $\mathrm{C}=\mathrm{O}$ groups (Fig. $5 \mathrm{c}$ ). Furthermore, XPS on $\mathrm{C} 1 \mathrm{~s}$ of 4-Cl-BQ@rGO composite electrode was further performed to understand the transformation between $\mathrm{C}=\mathrm{O}$ and $\mathrm{C}_{-} \mathrm{O}^{-}$groups (Fig. 5d). Compared with the $\mathrm{C} 1 s$ spectra of the pristine 4-ClBQ@rGO composite electrode, the characteristic peak of $\mathrm{C}=\mathrm{O}$ bonds at $288.1 \mathrm{eV}$ becomes invisible at a fully discharged state. Besides, a new peak at $285.5 \mathrm{eV}$ assigned to $\mathrm{C}-\mathrm{O}$ bonds emerges. Reversibly, these peaks corresponding to $\mathrm{C}=\mathrm{O}$ and $\mathrm{C}-\mathrm{O}$ bonds return to the initial state in recharged electrodes. There is a possible competition between protons and $\mathrm{Mn}^{2+}$ ions to react with 4-Cl-BQ molecules during the discharge process due to the coexistence of these two cations in electrolytes. Protons could coordinate with 4-Cl-BQ molecules to form dihydro-p-chloranil (4-Cl-HQ) in the acid electrolyte at discharged state ${ }^{56}$, whereas no characteristic peak of 4-Cl-HQ is observed in the XRD pattern of discharged products (Supplementary Fig. 26), suggesting that protons would not coordinate with $4-\mathrm{Cl}-\mathrm{BQ}$ molecules in the electrolyte solution we used. XPS spectra on Mn $2 p$ were further conducted to demonstrate whether $\mathrm{Mn}^{2+}$ ions in electrolyte coordinate with $4-\mathrm{Cl}-\mathrm{BQ}$ molecules. Two peaks belonging to $\mathrm{Mn}$ $2 p_{1 / 2}$ and $\mathrm{Mn} 2 p_{3 / 2}$ are observed at a fully discharged state (Fig. 5e), which indicates the $\mathrm{Mn}^{2+}$ ion coordination. Furthermore, the elemental mapping also demonstrates the existence of Mn in discharged products (Supplementary Figs. 27 and 28). It is 
consistent with the XPS results. These results imply the $\mathrm{Mn}^{2+}$ coordination/uncoordination in 4-Cl-BQ during the discharge/ charge process.

At a fully discharged state, one $\mathrm{Mn}^{2+}$ ion needs to coordinate with two $\mathrm{C}-\mathrm{O}^{-}$groups. However, owing to the long distance between two $\mathrm{C}-\mathrm{O}^{-}$groups in one $4-\mathrm{Cl}-\mathrm{BQ}$ molecule, $\mathrm{Mn}^{2+}$ ion would coordinate with adjacent two 4-Cl-BQ molecules during the discharge process. Thus, the nonsymmetrical crystal structure of 4Cl-BQ molecules results in two possible coordination sites of $\mathrm{Mn}^{2+}$ ions in 4-Cl-BQ crystals: (1) $\mathrm{Mn}^{2+}$ ion uptake occurs along the $c$ axis between adjacent 4-Cl-BQ molecules (4-Cl-BQ- $\mathrm{Mn}_{1}$ ); (2) $\mathrm{Mn}^{2+}$ ion uptake takes place along the $b$ axis between adjacent 4-Cl-BQ molecules (4-Cl-BQ- $\mathrm{Mn}_{2}$ ) (Fig. 5f). To understand where the $\mathrm{Mn}^{2+}$ ion coordinates with 4-Cl-BQ molecules at a fully discharged state, theoretical calculations with density functional theory (DFT) were conducted. The XRD pattern of optimized 4-Cl-BQ is consistent with 4-Cl-BQ@rGO electrodes (Supplementary Fig. 29). The calculated results show that the binding energy of $4-\mathrm{Cl}-\mathrm{BQ}-\mathrm{Mn}_{2}$ is lower than the case of $4-\mathrm{Cl}-\mathrm{BQ}-\mathrm{Mn}_{1}$ (Fig. $5 \mathrm{~g}$ ). Furthermore, in the simulated XRD pattern of $4-\mathrm{Cl}-\mathrm{BQ}-\mathrm{Mn}_{2}$, the peaks corresponding to (100), (200), and (300) planes are observed (Fig. 5h), which is consistent with the experimental XRD results. Therefore, 4-Cl-BQ$\mathrm{Mn}_{2}$ is the most likely structure of the discharged product. Owing to the strong electrostatic interactions between $\mathrm{Mn}^{2+}$ ions and $\mathrm{C}-\mathrm{O}^{-}$ groups, the $\mathrm{Mn}^{2+}$ ion coordination results in the decrease of the $\mathrm{O}-\mathrm{O}$ distance between $\mathrm{C}-\mathrm{O}^{-}$groups in adjacent 4-Cl-BQ molecules (Supplementary Fig. 30). Furthermore, we calculated the charge density difference of the discharge product (Fig. 5i). Electron deficient region is found around the coordinated $\mathrm{Mn}$ atoms, suggesting a significant electron transfer from $\mathrm{Mn}$ to $4-\mathrm{Cl}-\mathrm{BQ}^{57}$, which contributes to a more stable crystal structure of 4-Cl-BQ after $\mathrm{Mn}^{2+}$ coordination.

Opportunities and challenges of aqueous MIBs. The aqueous MIBs have some advantages over conventional rechargeable energy storage systems. Compared with $\mathrm{Pb}$-acid batteries, the aqueous MIBs show higher specific power (Fig. 6a). Moreover, at the high specific power, they can also deliver higher specific energy than aqueous and non-aqueous supercapacitors. Therefore, aqueous MIBs could be promising for large-scale electrochemical energy storage applications. In contrast with aqueous zinc-ion batteries, the motivations triggering the development of aqueous MIBs are related to the general features of Mn metal. Firstly, Mn metal is more abundant, more inexpensive, and with lower toxicity than $\mathrm{Zn}$ metal (Fig. 6b), which is important for evaluating sustainability and practical applications. Besides, aqueous MIBs could deliver higher specific energy when paired with the same redox couples, resulting from the lower standard reduction potential and higher capacity $(-1.19 \mathrm{~V}$ vs. SHE; $\left.976 \mathrm{mAh} \mathrm{g}^{-1}\right)$ of $\mathrm{Mn}$ than those of $\mathrm{Zn}(-0.76 \mathrm{~V}$ vs. SHE; $820 \mathrm{mAh}^{-1}$ ). In our case, although the $\mathrm{Mn} \| \mathrm{MnVO}$ cells display lower specific capacity (based on the mass of MnVO) than the case of $\mathrm{Zn} \| \mathrm{MnVO}$ cells, they can still deliver higher specific energy due to the higher discharge voltage (Supplementary Fig. 31). In addition, with the rational design of cathode architectures, aqueous MIBs could deliver stable cycling performance and excellent rate capability. More importantly, the rich valence states of manganese $\left(\mathrm{Mn}^{0}, \mathrm{Mn}^{2+}, \mathrm{Mn}^{3+}, \mathrm{Mn}^{4+}\right.$, and $\left.\mathrm{Mn}^{7+}\right)$ would provide great opportunities for the exploration of various manganese-based battery systems ${ }^{20}$.

In spite of the advantages mentioned above, there is still much work to do for MIBs to promote their practical applications. The main challenge is to improve the reversibility of Mn plating/ stripping in the charge/discharge process. $\mathrm{Mn}^{2+}$ ions could strip from $\mathrm{Mn} / \mathrm{C}$ anodes during discharging (Supplementary Fig. 32), leading to high cell discharge voltages of aqueous MIBs. However, in the reversible charging process, hydrogen evolution would occur at anode since the redox potential of hydrogen evolution is higher than that of $\mathrm{Mn}^{2+} / \mathrm{Mn}$, resulting in poor reversibility of the Mn plating/stripping process. During the hydrogen evolution, a large amount of $\mathrm{OH}^{-}$ions yields. These $\mathrm{OH}^{-}$ions further combine with $\mathrm{Mn}^{2+}$ ions to form $\mathrm{Mn}(\mathrm{OH})_{2}$ nanosheets on the surface of the anode (Supplementary Fig. 33). The $\mathrm{Mn}(\mathrm{OH})_{2}$ layer at the anode will impede ion transportation, degrading cycling stability (Supplementary Fig. 34 and Supplementary Note 3). Since such a side reaction occurs, the charge/discharge capacity degrades gradually after 100 charge/discharge cycles in the case of $\mathrm{Mn} \| \mathrm{MnVO}$ cells. In Mn\|4-Cl-BQ cells, the long cycling performance was also limited. To further promote the long cycling behavior, electrolyte or anode optimizing has to be considered. In the case of electrolytes, "water in salt" or molecular crowded electrolytes could be employed to broaden the voltage window of aqueous electrolytes and suppress the hydrogen evolution $^{1,58}$. Besides, the electrodeposition efficiency of $\mathrm{Mn}$ metal is also important for long cycling performance. Some strategies, such as lattice matching, alloying of Mn metal, and the formation of a favorable solid electrolyte interphase on the anode surface, could be developed to improve the reversibility of $\mathrm{Mn}$ plating/striping ${ }^{59}$. In addition, the design of active materials is also crucial to further improve the electrochemical performance of aqueous MIBs. Moreover, the exploration of cathode materials is accompanied by the emergence of other energy storage mechanisms.
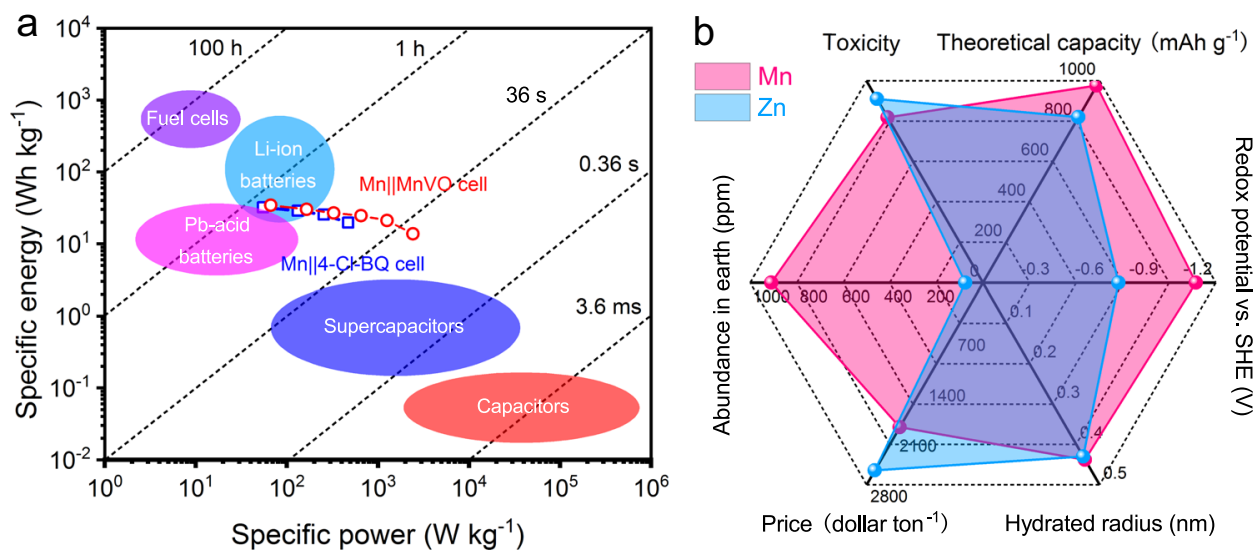

Fig. 6 Comparison of aqueous MIBs with other energy storage systems. a Ragone plot showing the specific energy and power of the aqueous Mn cells with various commercial energy storage devices ${ }^{60}$. b Comparison of the general features between $\mathrm{Mn}$ and $\mathrm{Zn}^{6}$. 


\section{Discussion}

The reversible $\mathrm{Mn}^{2+}$ ion intercalation process was achieved in aqueous battery systems, in which two kinds of cathodes, an inorganic material, and organic material, have been proved to possess the $\mathrm{Mn}^{2+}$ ion storage ability. The layered MnVO cathode displays the reversible $\mathrm{Mn}^{2+}$ ion insertion/extraction mechanism with fast kinetics and stable cycling performance during the discharge/charge process. The $\mathrm{Mn} \| \mathrm{MnVO}$ cell can be fully charged to $1.9 \mathrm{~V}$ at around $20 \mathrm{~s}\left(10.0 \mathrm{~A} \mathrm{~g}^{-1}, 64.8 \mathrm{Wh} \mathrm{kg}^{-1}\right)$, suggesting the fast-charging capabilities. Another organic cathode of 4-Cl-BQ exhibits an $\mathrm{Mn}^{2+}$ ion coordination/uncoordination with the transformation between $\mathrm{C}=\mathrm{O}$ and $\mathrm{C}-\mathrm{O}^{-}$groups. The DFT calculations suggest that one $\mathrm{Mn}^{2+}$ ion will coordinate with

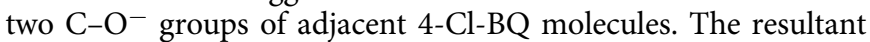
$\mathrm{Mn}|| 4-\mathrm{Cl}-\mathrm{BQ}$ cell shows a stable discharge voltage at $\sim 1.37 \mathrm{~V}$. This work will broaden the battery research to $\mathrm{Mn}^{2+}$ ions as charge carriers and also help to improve the electrochemical performance of aqueous batteries.

\section{Methods}

Materials. Vanadium pentoxide $\left(\mathrm{V}_{2} \mathrm{O}_{5}, 99 \%\right)$, manganese sulfate monohydrate $\left(\mathrm{MnSO}_{4} \cdot \mathrm{H}_{2} \mathrm{O}, 99 \%\right)$, manganese nitrate tetrahydrate $\left(\mathrm{Mn}\left(\mathrm{NO}_{3}\right)_{2} \cdot 4 \mathrm{H}_{2} \mathrm{O}, 98 \%\right)$ and hydrogen peroxide $\left(\mathrm{H}_{2} \mathrm{O}_{2}, 30 \%\right)$ were purchased from Aladdin. Manganese chloride tetrahydrate $\left(\mathrm{MnCl}_{2} \cdot 4 \mathrm{H}_{2} \mathrm{O}, 99.9 \%\right)$ and $\mathrm{N}$-methyl-2-pyrrolidone (NMP, 99.5\%) were purchased from Macklin. Super P, polyvinylidene fluoride (PVDF) and trichloromethane $\left(\mathrm{CHCl}_{3}, 99 \%\right)$ were from Sinopharm Chemical Reagent Co., Ltd. Ttetrachloro-1,4-benzoquinone (4-Cl-BQ, 98\%) was from Meryer Chemical Technology Co., Ltd. Glass fiber (Grade GF/A with a thickness of $260 \mu \mathrm{m}$ ) was purchased from Whatman. Manganese bis(trifluoromethanesulfonate) $\left(\mathrm{Mn}\left(\mathrm{CF}_{3} \mathrm{SO}_{3}\right)_{2}\right)$ and zinc bis(trifluoromethanesulfonate) $\left(\mathrm{Zn}\left(\mathrm{CF}_{3} \mathrm{SO}_{3}\right)_{2}, 97.5 \%\right)$ were from Sigma-Aldrich and J\&K Scientific Ltd., respectively. They were purified via filtration by syringe before using. A measure of $0.353 \mathrm{~g}$ of $\mathrm{Mn}\left(\mathrm{CF}_{3} \mathrm{SO}_{3}\right)_{2}$ was added into $1 \mathrm{~mL}$ deionized water under magnetic stirring. The $\mathrm{Mn}\left(\mathrm{CF}_{3} \mathrm{SO}_{3}\right)_{2}$ aqueous solution was transferred into a syringe filter and then purified by the aqueous syringe-driven filter to obtain $\mathrm{Mn}\left(\mathrm{CF}_{3} \mathrm{SO}_{3}\right)_{2}$ electrolyte $(1 \mathrm{M})$. The purification of $\mathrm{Zn}\left(\mathrm{CF}_{3} \mathrm{SO}_{3}\right)_{2}$ electrolyte $(1 \mathrm{M})$ follows the same steps. $\mathrm{Mn}$ particles (99.8\%, Supplementary Fig. 35a-c) and Zn foil (99.9\%) were purchased from HeBei Xindun of China and Alfa Aesar, respectively. They were used directly without any treatment. Stainless steel $(>99 \%, \sim 56 \mu \mathrm{m})$ and carbon felts $(\sim 330 \mu \mathrm{m})$ were purchased from Tianhong Wangye and Taiwan Tanneng of China, respectively.

Electrode preparation. A $2 \mathrm{mmol}$ of commercial $\mathrm{V}_{2} \mathrm{O}_{5}$ powder was dissolved into $50 \mathrm{~mL}$ of deionized water with $2 \mathrm{~mL}$ of $\mathrm{H}_{2} \mathrm{O}_{2}$. A $0.2 \mathrm{mmol}$ of $\mathrm{MnSO}_{4}$ was dissolved into $30 \mathrm{~mL}$ of deionized water. These two solutions were transferred to a $100 \mathrm{~mL}$ Teflon-lined stainless steel autoclave and then heated at $120^{\circ} \mathrm{C}$ for $5 \mathrm{~h}$. After the reaction, the suspension was washed with deionized water several times and finally, the $\mathrm{MnVO}$ nanosheets were obtained by freeze-drying $\left(-80^{\circ} \mathrm{C}\right)$. MnVO nanosheets, super $\mathrm{P}$, and PVDF were mixed with a weight ratio of 7:2:1 by NMP. The slurry was grinded manually in mortar for $1 \mathrm{~h}$ and then coated on stainless steel $\left(0.785 \mathrm{~cm}^{2}\right)$. After drying at $80^{\circ} \mathrm{C}$ for $12 \mathrm{~h}$ under vacuum, MnVO cathode was achieved. The mass loading of MnVO in the cathode $(\sim 80 \mu \mathrm{m}$, which is the thickness of stainless steel with the coating) was $\sim 1.0 \mathrm{mg} \mathrm{cm}^{-2} \pm 0.5 \mathrm{mg} \mathrm{cm}^{-2}$.

$1 \mathrm{~mL}$ Vitamin $\mathrm{C}\left(1 \mathrm{~mol} \mathrm{~L}^{-1}\right)$ and $20 \mathrm{~mL}$ GO dispersion $\left(1 \mathrm{mg} \mathrm{mL}^{-1}\right)$ were mixed and then sealed in a $50 \mathrm{~mL}$ Teflon lined stainless steel autoclave. The mixed solution was maintained at $95{ }^{\circ} \mathrm{C}$. After $10 \mathrm{~h}, \mathrm{rGO}$ hydrogel was achieved. It was washed, cut, and then freeze-dried to obtain rGO foams $(750 \mu \mathrm{m} \pm 250 \mu \mathrm{m})$. Commercial 4 -Cl$\mathrm{BQ}$ was dissolved in $\mathrm{CHCl}_{3}$ to obtain the yellow solution with a concentration of $2 \mathrm{mg} \mathrm{mL}^{-1}$. Then, single-channel adjustable pipettes were employed to drip the resultant solution with a specific volume of $\sim 500 \mu \mathrm{L} / \mathrm{cm}^{-2}$ into rGO foams. After drying, 4-Cl-BQ@rGO electrodes (4-Cl-BQ, 40\%) were obtained. The mass loading of 4 -Cl-BQ in electrodes was $\sim 1.0 \mathrm{mg} \mathrm{cm}^{-2} \pm 0.5 \mathrm{mg} \mathrm{cm}^{-2}$.

Commercial Mn particles, super P, and PVDF were mixed with a weight ratio of $8: 1: 1$ by NMP. The slurry was grinded manually in mortar for $1 \mathrm{~h}$ and then coated onto carbon felts $\left(0.785 \mathrm{~cm}^{2}\right)$. The carbon felts were then dried at $80{ }^{\circ} \mathrm{C}$ for $12 \mathrm{~h}$ under vacuum to obtain the $\mathrm{Mn} / \mathrm{C}$ composite anodes (Supplementary Fig. 35d). The thickness of the carbon felt with the Mn/C coating was $\sim 500 \mu \mathrm{m}$ and the mass loading of $\mathrm{Mn}$ metal was $>30 \mathrm{mg} \mathrm{cm}^{-2}$.

Electrochemical measurement. All the electrochemical measurements were carried out using CR2032 coin cells, in which the areas of electrodes and glass fiber separators were 0.785 and $2.01 \mathrm{~cm}^{2}$, respectively. The amount of electrolyte in a cell was $200 \mu \mathrm{L}$. Mn metal cells were assembled with MnVO or 4-Cl-BQ@rGO cathode, $\mathrm{Mn} / \mathrm{C}$ anode, and $1 \mathrm{M} \mathrm{Mn}$-containing aqueous electrolyte. $\mathrm{Zn} \| \mathrm{MnVO}$ cells were assembled with $\mathrm{MnVO}$ cathode, $\mathrm{Zn}$ foil anode, and $1 \mathrm{M} \mathrm{Zn}\left(\mathrm{CF}_{3} \mathrm{SO}_{3}\right)_{2}$ electrolyte.
$\mathrm{Mn} / \mathrm{C} \| \mathrm{Mn} / \mathrm{C}$ symmetric cells were tested with identical $\mathrm{Mn} / \mathrm{C}$ electrodes and $1 \mathrm{M}$ $\mathrm{Mn}\left(\mathrm{CF}_{3} \mathrm{SO}_{3}\right)_{2}$ electrolyte.

$\mathrm{CV}$ (scan rate: $1.0-3.0 \mathrm{mV} \mathrm{s}^{-1}$ ) and linear sweep voltammetry (LSV) (scan rate $10.0 \mathrm{mV} \mathrm{s}^{-1}$ ) measurements were carried out with electrochemical workstations (CHI 660E). GCD (specific current: $0.05-10.0 \mathrm{Ag}^{-1}$ ) and GITT measurements (specific current: $0.2 \mathrm{~A} \mathrm{~g}^{-1}$ ) were performed on a cell test system (LAND, CT2001A). The voltage windows of Mn||MnVO, $\mathrm{Zn}|| \mathrm{MnVO}$, and $\mathrm{Mn}|| 4-\mathrm{Cl}-\mathrm{BQ}$ cells were 1.0-1.9, 0.7-1.6, and 0.8-1.8 V, respectively. Electrochemical impedance spectroscopy measurements of the $\mathrm{Mn} / \mathrm{MnVO}$ batteries were examined in a twoelectrode cell configuration, in which $\mathrm{Mn} / \mathrm{C}, \mathrm{MnVO}$, and $1 \mathrm{M} \mathrm{Mn}\left(\mathrm{CF}_{3} \mathrm{SO}_{3}\right)_{2}$ or $\mathrm{MnSO}_{4}$ served as an anode, cathode, and electrolyte, respectively. The tests were performed in a frequency range of $100 \mathrm{kHz}$ to $10 \mathrm{mHz}$ (Zennium E, Zahner Elektrik $\mathrm{GmbH} \&$ Co. KG) by applying a disturbance amplitude of $5 \mathrm{mV}$. The number of data points was 59 . The quasi-stationary potential was maintained during the measurement. All the electrochemical energy storage tests were carried out at around $25^{\circ} \mathrm{C}$ in an environmental chamber.

The electrodeposition of Mn metal on stainless steel was carried out by LSV via two-electrode cell configuration, where stainless steel, $\mathrm{Mn} / \mathrm{C}$, and $1 \mathrm{M} \mathrm{Mn-}$ contained aqueous solution served as working electrode, a counter electrode, and electrolyte, respectively. The LSV curves were measured from the open-circuit voltage to $-1.5 \mathrm{~V}$ with a scan rate of $10 \mathrm{mV} \mathrm{s}^{-1}$. The deposition in different aqueous electrolytes $\left(\mathrm{MnSO}_{4}\right.$ or $\left.\mathrm{Mn}\left(\mathrm{CF}_{3} \mathrm{SO}_{3}\right)_{2}\right)$ was performed following the same steps.

The specific energy $\left(E, \mathrm{Wh} \mathrm{kg}^{-1}\right)$ and power $\left(P, \mathrm{~W} \mathrm{~kg}^{-1}\right)$ of batteries based on active materials were calculated as follows ${ }^{49}$ :

$$
\begin{gathered}
E=\frac{\int I V(t) d t}{3.6 m} \\
P=\frac{3600 E}{t}
\end{gathered}
$$

in which $I(\mathrm{~A})$ and $V(\mathrm{~V})$ are the current and voltage of the cell, $t(\mathrm{~s})$ is the discharge time, and $m(\mathrm{~g})$ is the weight of active material. The voltage of the cell was the average discharge voltage, which was at the half of the discharge capacity in discharging process. In calculating the energy and power densities in Fig. 6a, the mass of devices is regarded as five times of the active materials in cathodes.

Characterization. The morphologies of MnVO nanosheets, $\mathrm{MnVO}$ cathodes, commercial $\mathrm{Mn}$ particles, $\mathrm{Mn} / \mathrm{C}$ composite anodes, rGO foams, commercial 4-ClBQ sheets, and 4-Cl-BQ@rGO composites were characterized by field-emission scanning electron microscopy (JEOLJSM-7500F) equipped with EDX for elemental analysis. The microstructure was characterized via TEM (Talos F200X G2) equipped with EDX for elemental analysis. XRD patterns were obtained from Rigaku Ultima IV with Cu Ka radiation. FTIR spectra were collected on Bruker Tensor II. Raman spectra were obtained from a confocal Raman microscope (DXR Thermo Fisher Scientific) with a $532 \mathrm{~nm}$ excitation from an argon-ion laser. XPS tests were performed through PerkinElmer PHI 1600 ESCA. Thermogravimetric analysis (Netzsch STA 449 F3 Jupiter analyzer) was carried out from room temperature to $800^{\circ} \mathrm{C}$ (Ar flow, $10^{\circ} \mathrm{C} \mathrm{min}-1$ ). ICP-AES tests were carried out from PerkinElmer Optima 8300. The contact angles of electrolytes were obtained on Physics OCA 25. For the ex situ measurements at different charge/discharge states, the electrodes were washed with deionized water more than 5 times and then dried in the atmosphere for further characterization without any specific transport holder.

The amount of the inserted/extracted $\mathrm{Mn}^{2+}$ ions in $\mathrm{MnVO}$ was determined by ICP-AES, which was obtained according to the formula ${ }^{36}$ :

$$
I=a C^{b}
$$

where $I$ and $C$ are the intensity of characteristic spectra and the concentration of metal elements, respectively; $a$ and $b$ are adjustable parameters. The standard curves of $\mathrm{Mn}$ and $\mathrm{V}$ were obtained via measuring standard solutions with different concentrations of $\mathrm{Mn}$ and $\mathrm{V}$. The MnVO electrodes were first washed with deionized water 5 times and then dissolved in $5 \mathrm{~mL} 0.5 \mathrm{M} \mathrm{H}_{2} \mathrm{SO}_{4}$. After purifying via removing super $\mathrm{P}$ and $\mathrm{PVDF}$, the solution was achieved and then diluted to $500 \mathrm{~mL}$ for further characterization. The molar ratios of $\mathrm{Mn}$ and $\mathrm{V}$ could be quantified according to the above formula.

Computational methods. The spin-polarized first-principles calculations based on the DFT were performed using the Vienna Ab-initio Simulation Package with projector-augmented-wave pseudopotentials. The generalized gradient approximation of Perdew-Burke-Ernzerhof was employed for the exchange-correlation function. Cutoff energy of $500 \mathrm{eV}$ was selected as the plane-wave basis to ensure the precision of the calculations using a $2 \times 3 \times 2$ Monkhorst-Pack reciprocal space grid of k-points for a single unit cell. The relaxation of the electronic degrees of freedom was assumed to be converged when the total energy change between the two electronic optimization steps was smaller than $1 \times 10^{-6} \mathrm{eV}$. Geometry relaxation was carried out before studying the structural properties and total energy until all forces on each atom were below $0.02 \mathrm{eV}^{-1}$. 


\section{Data availability}

The authors declare that all the relevant data are available within the paper and its Supplementary Information file or from the corresponding author upon reasonable request.

Received: 28 June 2021; Accepted: 9 November 2021; Published online: 30 November 2021

\section{References}

1. Suo, L. et al. "Water-in-salt" electrolyte enables high-voltage aqueous lithiumion chemistries. Science 350, 938-945 (2015).

2. Huang, Z. et al. Manipulating anion intercalation enables a high-voltage aqueous dual ion battery. Nat. Commun. 12, 3106 (2021).

3. Yang, C. et al. Aqueous Li-ion battery enabled by halogen conversionintercalation chemistry in graphite. Nature 569, 245-250 (2019).

4. Yamada, Y. et al. Hydrate-melt electrolytes for high-energy-density aqueous batteries. Nat. Energy 1, 16129 (2016).

5. Yang, C. et al. $4.0 \mathrm{~V}$ aqueous Li-ion batteries. Joule 1, 122-132 (2017).

6. Wu, X. et al. A rechargeable battery with an iron metal anode. Adv. Funct. Mater. 29, 1900911 (2019).

7. Xu, C., Li, B., Du, H. \& Kang, F. Energetic zinc ion chemistry: the rechargeable zinc ion battery. Angew. Chem. Int. Ed. 51, 933-935 (2012).

8. Yan, C. et al. Architecting a stable high-energy aqueous Al-ion battery. J. Am. Chem. Soc. 142, 15295-15304 (2020).

9. Wang, S. et al. Non-metal ion co-insertion chemistry in aqueous $\mathrm{Zn} / \mathrm{MnO}_{2}$ batteries. Angew. Chem. Int. Ed. 60, 7056-7060 (2021).

10. Tang, $\mathrm{X}$. et al. A universal strategy towards high-energy aqueous multivalention batteries. Nat. Commun. 12, 2857 (2021).

11. Liu, Z. et al. Voltage issue of aqueous rechargeable metal-ion batteries. Chem. Soc. Rev. 49, 180-232 (2019)

12. Qiu, H. et al. Zinc anode-compatible in-situ solid electrolyte interphase via cation solvation modulation. Nat. Commun. 10, 5374 (2019).

13. $\mathrm{Wu}, \mathrm{C}$. et al. Electrochemically activated spinel manganese oxide for rechargeable aqueous aluminum battery. Nat. Commun. 10, 73 (2019).

14. Yang, H. et al. Progress in rechargeable aqueous zinc-and aluminum-ion battery electrodes: challenges and outlook. Angew. Chem. Int. Ed. 3, 1800111 (2019).

15. Kravchyk, K. V. \& Kovalenko, M. V. The pitfalls in nonaqueous electrochemistry of Al-ion and $\mathrm{Al}$ dual-ion batteries. Adv. Energy Mater. 10, 2002151 (2020).

16. Shen, X. et al. Ultra-fast charging in aluminum-ion batteries: electric double layers on active anode. Nat. Commun. 12, 820 (2021).

17. Faegh, E., Ng, B., Hayman, D. \& Mustain, W. E. Practical assessment of the performance of aluminium battery technologies. Nat. Energy 6, 21-29 (2020).

18. Tu, J. et al. Nonaqueous rechargeable aluminum batteries: progresses, challenges, and perspectives. Chem. Rev. 121, 4903-4961 (2021).

19. Chao, D. et al. Roadmap for advanced aqueous batteries: from design of materials to applications. Sci. Adv. 6, eaba4098 (2020).

20. Chen, W. et al. A manganese-hydrogen battery with potential for grid-scale energy storage. Nat. Energy 3, 428-435 (2018).

21. Zhang, K. et al. Nanostructured Mn-based oxides for electrochemical energy storage and conversion. Chem. Soc. Rev. 44, 699-728 (2015).

22. Díaz-Arista, P. et al. EQCM study of the electrodeposition of manganese in the presence of ammonium thiocyanate in chloride-based acidic solutions. Electrochim. Acta 51, 4393-4404 (2006).

23. Dong, $\mathrm{H}$. et al. High-power Mg batteries enabled by heterogeneous enolization redox chemistry and weakly coordinating electrolytes. Nat. Energy $\mathbf{5}$, 1043-1050 (2020).

24. Huang, S., Zhu, J., Tian, J. \& Niu, Z. Recent progress in the electrolytes of aqueous zinc-ion batteries. Chem. Eur. J. 25, 14480-14494 (2019).

25. Zhang, N. et al. Cation-deficient spinel $\mathrm{ZnMn}_{2} \mathrm{O}_{4}$ cathode in $\mathrm{Zn}\left(\mathrm{CF}_{3} \mathrm{SO}_{3}\right)_{2}$ electrolyte for rechargeable aqueous $\mathrm{Zn}$-ion battery. J. Am. Chem. Soc. 138 12894-12901 (2016).

26. Wan, F. et al. An aqueous rechargeable zinc-organic battery with hybrid mechanism. Adv. Funct. Mater. 28, 1804975 (2018).

27. Liang, G., Mo, F., Ji, X. \& Zhi, C. Non-metallic charge carriers for aqueous batteries. Nat. Rev. Mater. 6, 109-123 (2020).

28. $\mathrm{Xu}, \mathrm{Y}$. et al. Vanadium oxide pillared by interlayer $\mathrm{Mg}^{2+}$ ions and water as ultralong-life cathodes for magnesium-ion batteries. Chemistry 5, 1194-1209 (2019).

29. $\mathrm{Xu}$, X. et al. Bilayered $\mathrm{Mg}_{0.25} \mathrm{~V}_{2} \mathrm{O}_{5} \cdot \mathrm{H}_{2} \mathrm{O}$ as a stable cathode for rechargeable Ca-ion batteries. ACS Energy Lett. 4, 1328-1335 (2019).

30. Kundu, D., Adams, B. D., Duffort, V., Vajargah, S. H. \& Nazar, L. F. A highcapacity and long-life aqueous rechargeable zinc battery using a metal oxide intercalation cathode. Nat. Energy 1, 16119 (2016).
31. Yan, M. et al. Water-lubricated intercalation in $\mathrm{V}_{2} \mathrm{O}_{5} \cdot \mathrm{nH}_{2} \mathrm{O}$ for high-capacity and high-rate aqueous rechargeable zinc batteries. Adv. Mater. 30, 1703725 (2018).

32. Lu, Y. \& Chen, J. Prospects of organic electrode materials for practical lithium batteries. Nat. Rev. Chem. 4, 127-142 (2020).

33. Tie, Z. \& Niu, Z. Design strategies for high-performance aqueous Zn/organic batteries. Angew. Chem. Int. Ed. 59, 21293-21303 (2020).

34. Kim, D. et al. Rechargeable aluminium organic batteries. Nat. Energy 4, 51-59 (2018).

35. Zhao, Q. et al. High-capacity aqueous zinc batteries using sustainable quinone electrodes. Sci. Adv. 4, eaao1761 (2018)

36. Wan, F. et al. Aqueous rechargeable zinc/sodium vanadate batteries with enhanced performance from simultaneous insertion of dual carriers. Nat. Commun. 9, 1656 (2018).

37. Zhao, Q. et al. Proton intercalation/de-intercalation dynamics in vanadium oxides for aqueous aluminum electrochemical cells. Angew. Chem. Int. Ed. 59, 3048-3052 (2019)

38. Wang, L., Huang, K., Chen, J., Zheng, J. \& Maia, Y. Ultralong cycle stability of aqueous zinc-ion batteries with zinc vanadium oxide cathodes. Sci. Adv. $\mathbf{5}$ eaax4279 (2019)

39. He, P. et al. High-performance aqueous zinc-ion battery based on layered $\mathrm{H}_{2} \mathrm{~V}_{3} \mathrm{O}_{8}$ nanowire cathode. Small 13, 1702551 (2017)

40. Zhang, G. et al. Rich alkali ions preintercalated vanadium oxides for durable and fast zinc-ion storage. ACS Energy Lett. 6, 2111-2120 (2021)

41. Dong, $\mathrm{S}$. et al. Ultra-fast $\mathrm{NH}_{4}{ }^{+}$storage: strong $\mathrm{H}$ bonding between $\mathrm{NH}_{4}{ }^{+}$and bi-layered $\mathrm{V}_{2} \mathrm{O}_{5}$. Chemistry 5, 1537-1551 (2019).

42. Kundu, D. et al. Organic cathode for aqueous $\mathrm{Zn}$-ion batteries: taming a unique phase evolution toward stable electrochemical cycling. Chem. Mater. 30, 3874-3881 (2018)

43. Tie, Z., Liu, L., Deng, S., Zhao, D. \& Niu, Z. Proton insertion chemistry of Zn/ organic battery. Angew. Chem. Int. Ed. 59, 4920-4924 (2020).

44. Guo, Z. et al. Environment-friendly and flexible aqueous zinc battery using an organic cathode. Angew. Chem. Int. Ed. 57, 11737-11741 (2018).

45. Guo, Z. et al. An organic/inorganic electrode-based hydronium-ion battery. Nat. Commun. 11, 959 (2020)

46. Emanuelsson, R., Sterby, M., Stromme, M. \& Sjodin, M. An all-organic proton battery. J. Am. Chem. Soc. 139, 4828-4834 (2017).

47. Liang, Y. et al. Universal quinone electrodes for long cycle life aqueous rechargeable batteries. Nat. Mater. 16, 841-848 (2017).

48. Jiang, L. et al. Building aqueous K-ion batteries for energy storage. Nat. Energy 4, 495-503 (2019)

49. Han, C., Li, H., Li, Y., Zhu, J. \& Zhi, C. Proton-assisted calcium-ion storage in aromatic organic molecular crystal with coplanar stacked structure. Nat. Commun. 12, 2400 (2021).

50. Wang, F. et al. High-voltage aqueous magnesium ion batteries. ACS Cent. Sci. 3, 1121-1128 (2017).

51. $\mathrm{Li}$, Y. et al. High-energy-density quinone-based electrodes with $[\mathrm{Al}(\mathrm{OTF})]^{2+}$ storage mechanism for rechargeable aqueous aluminum batteries. Adv. Funct. Mater. 31, 2102063 (2021).

52. Wang, Y. et al. Binding zinc ions by carboxyl groups from adjacent molecules toward long-life aqueous zinc-organic batteries. Adv. Mater. 32, 2000338 (2020).

53. Li, Y. et al. Rechargeable aqueous polymer-air batteries based on polyanthraquinone anode. Chemistry 5, 2159-2170 (2019).

54. Zhang, N. et al. Hydrated layered vanadium oxide as a highly reversible cathode for rechargeable aqueous zinc batteries. Adv. Funct. Mater. 29, 1807331 (2019)

55. Bi, S. et al. Free-standing three-dimensional carbon nanotubes/amorphous $\mathrm{MnO}_{2}$ cathodes for aqueous zinc-ion batteries with superior rate performance. Mater. Today Energy 18, 100548 (2020).

56. Yue, F. et al. Ultralow temperature aqueous battery with proton chemistry. Angew. Chem. Int. Ed. 60, 13882-13886 (2021).

57. Wei, Z. et al. Reversible intercalation of methyl viologen as a dicationic charge carrier in aqueous batteries. Nat. Commun. 10, 3227 (2019).

58. Xie, Z., Liang, Z. \& Lu, Y. Molecular crowding electrolytes for high-voltage aqueous batteries. Nat. Mater. 19, 1006-1011 (2020).

59. Zheng, J. et al. Reversible epitaxial electrodeposition of metals in battery anodes. Science 366, 645-648 (2019).

60. Jia, X., Liu, C., Neale, Z. G., Yang, J. \& Cao, G. Active materials for aqueous zinc ion batteries: synthesis, crystal structure, morphology, and electrochemistry. Chem. Rev. 120, 7795-7866 (2020).

\section{Acknowledgements}

This work was supported by the National Natural Science Foundation of China (51822205 and 21875121), Natural Science Foundation of Tianjin (18JCJQJC46300 and 19JCZDJC31900), Ministry of Education of China (B12015), and "Frontiers Science Center for New Organic Matter”, Nankai University (Grant No. 63181206). 


\section{Author contributions}

Z.N. and S.B. conceived the idea. S.B. designed and performed the experiments. S.W calculated the $\mathrm{Mn}^{2+}$ ion coordination sites in 4-Cl-BQ crystals. Z.T. and F.Y. contributed to the material synthesis of MnVO nanosheets and rGO foams. Z.N. and S.B. wrote the paper. All authors took part in the result discussion and data analysis.

\section{Competing interests}

The authors declare no competing interests.

\section{Additional information}

Supplementary information The online version contains supplementary material available at https://doi.org/10.1038/s41467-021-27313-5.

Correspondence and requests for materials should be addressed to Zhiqiang Niu.

Peer review information Nature Communications thanks the anonymous, reviewer(s) for their contribution to the peer review of this work.

Reprints and permission information is available at http://www.nature.com/reprints
Publisher's note Springer Nature remains neutral with regard to jurisdictional claims in published maps and institutional affiliations.

\begin{abstract}
(c) (i) Open Access This article is licensed under a Creative Commons Attribution 4.0 International License, which permits use, sharing, adaptation, distribution and reproduction in any medium or format, as long as you give appropriate credit to the original author(s) and the source, provide a link to the Creative Commons license, and indicate if changes were made. The images or other third party material in this article are included in the article's Creative Commons license, unless indicated otherwise in a credit line to the material. If material is not included in the article's Creative Commons license and your intended use is not permitted by statutory regulation or exceeds the permitted use, you will need to obtain permission directly from the copyright holder. To view a copy of this license, visit http://creativecommons.org/ licenses/by/4.0/.
\end{abstract}

(C) The Author(s) 2021 